\title{
Patient Psychopathology and the Management of Clinical Dilemmas in Psychotherapy: A Qualitative Analysis of Clinical Decision-Making
}

\author{
Sarah B. Trasmundi ${ }^{1}$, Marie S. Bloch ${ }^{2}$, Stine S. Høgenhaug ${ }^{2}$, Vicki T. Jensen ${ }^{2}$, Katharina K. Wrist ${ }^{2}$, \\ Thomas W. Jensen ${ }^{1} \&$ Sune V. Steffensen ${ }^{1}$ \\ ${ }^{1}$ University of Southern Denmark, Campusvej, Odense M, Denmark \\ ${ }^{2}$ The Psychiatry, The North Denmark Region, Brønderslev, Denmark \\ Correspondence: Sarah Bro Trasmundi University of Southern Denmark, Campusvej, 55, 5230 Odense M, \\ Denmark. E-mail: sarbro@sdu.dk
}

Received: December 10, 2019 Accepted: March 10, 2020 Online Published: March 20, 2020

doi:10.5539/jedp.v10n1p29 URL: http://doi.org/10.5539/jedp.v10n1p29

\begin{abstract}
Introduction: Clinical dilemma management is an important part of daily decision-making processes in psychotherapy, and hence important for the quality of mental healthcare. However, the situated particularities of such dilemmas have been given little systematic attention - both in research and in practice, even though an improved understanding of the nature of clinical dilemmas is a central key to managing dilemmas successfully.
\end{abstract}

Method: Eight cases of authentic clinical dilemma management in psychotherapy have been analysed from the perspective of interaction analysis and psychopathology. The article uses video data and narrative interviews from a larger cognitive ethnography study conducted at a psychiatric Hospital in Denmark.

Results: The analysis demonstrates how clinical dilemma management in psychotherapy is particularly difficult due to the nature of a patient's psychopathology. Thus, it is often difficult to discern whether a given dilemma is intrinsically ethical, or if it is a manifestation of the patient's pathology. Two overall interaction patterns were identified: In the first pattern, the therapist fails to manage the clinical decision-making in accordance with the therapeutic goal, which strengthens the patient's psychopathological behaviour, for instance by giving in and do what the patient demands. In the second pattern, the therapist uses the situation as an opportunity to work with the patient's psychopathological behaviour in situated interaction.

Conclusion: This article presents a model for integrating an understanding of patient pathology into clinical and ethical decision-making. It establishes a window into how psychotherapists manage clinical dilemmas (successfully or not) through interaction. This illustration might impact on how we address, evaluate and understand clinical and ethical dilemma management, which again can contribute to the reduction of moral distress amongst healthcare practitioners, as well as amongst patients.

Keywords: psychotherapy, clinical dilemmas, ethical dilemmas, dilemma management, clinical decision-making, interaction, psychopathology bias

\section{Introduction: Patient Pathologies, Clinical Challenges and Decision-Making in Psychotherapy}

This article presents a model for integrating an understanding of patient psychopathology into clinical decision-making. Clinical dilemma management is an important part of daily decision-making processes in psychotherapy and hence important for the quality in mental healthcare. However, such challenges have been given little systematic attention - both in research and in practices (Molewijk and Reiter-Theil, 2016; Bruun et al., 2018). Some valuable initiatives to provide ethical support for clinical practice have been implemented (e.g. initiative such as ethics committees, ethics consultants and ethical reflection groups, cf. Bruun et al., 2018). While this focus opens up for how such boards and initiatives can be used to guide practice, it provides little insight into how clinical dilemmas are managed in interaction where psychopathologies are manifested in ways that complicate decision-making significantly.

This article applies a broad focus on clinical challenges and dilemmas, whereof many are ethical in nature. A standard definition of an ethical dilemma is: "the need to choose from among two or more morally acceptable options or between equally unacceptable courses of action, when one choice prevents selection of the other." (Ong et al., 2012) Beauchamp and Childress (1979) propose to evaluate such dilemmas in terms of four principles of 
biomedical ethics: autonomy, beneficence, non-maleficence, and justice (Beauchamp and Childress, 1979). Reflecting about an ethical dilemma in this respect is a valuable perspective, but as we demonstrate in section 3, it is difficult to practice, as dilemmas emerge and develop in interaction and need to be managed in situ. We therefore propose to expand the perspective of dilemma-based decision-making to include a practical/interactional perspective, where clinical evaluation is a messy, bodily and on-going activity that needs to be managed in real-time with the patient and in relation to the patient's psychopathology. Literature on clinical and ethical dilemmas serves as a background into which our thinking about patient pathologies should be integrated.

The overall idea of this article is that when it comes to ethical decision-making and clinical challenges, one must consider the psychopathology and relational history of the patient, as well as the current relationship with the therapist. Thus, there is a tendency for patients to exhibit psychopathological behaviour when they find themselves in stressful situations. Such instances where they become cognitively and emotionally overwhelmed, give rise to dilemma-based interactions where difficult and consequential decision-making processes are required. Accordingly, we need to understand how clinical dilemmas emerge and develop in interaction, and how they are being managed in interaction.

The purpose of this article is (1) to demonstrate how clinical dilemma management in psychotherapy is particularly difficult due to the nature of a patient's psychopathology, which is often manifested alongside the dilemma, and (2) to suggest how such dilemmas can be approached as a therapeutic-relevant possibility for managing patient interaction. The rationale for the latter is that such behaviour is most often a manifestation of psychopathological behaviour, grounded in past experiences and reenacted in the present interaction. This line of work seeks to establish a window into how psychotherapists manage such dilemmas (successfully or unsuccessfully), not by logical deduction, but through interaction with their patients. This systematic demonstration might impact on how we address, evaluate and understand clinical dilemma management, which again can contribute to the reduction of moral distress amongst therapists and patients, as it opens up for a more realistic view on clinical dilemmas in real-life psychotherapy. This work further helps mapping out some general dynamics in dilemma-based interactions that appear to be related to the reenactment of psychopathological behaviour.

\section{Method}

\subsection{Study design, Data and Research Ethics}

The dataset used in this article comes from a large cognitive, ethnographic study conducted at a Danish Psychiatric Hospital. The total dataset consists of video-recordings of authentic therapeutic conversations between therapists and patients diagnosed with social anxiety disorders and/or personality disorders. Altogether, 26 patients were recruited for the study, and all sessions of each patient (i.e. between 20 and 50 sessions per patient) were recorded. This study was reported to the South Danish Regional Committee on Health Research Ethics and the Legal office of the University in which the project is registered. The Committee on Health Research Ethics has ruled that according to Danish law, this study does not require the Committee's ethical approval. All patients and therapists have given their written consent. This article uses anonymised versions of the data. Written informed consent was obtained from the participants for publication of their cases and any aecompanying tables. The data used in this article has not previously been published. As mentioned above, this paper presents a model for integrating an understanding of patient pathology and clinical decision-making as it is being managed in real-life interaction. Accordingly, we collected a number of cases to illustrate the application of that model. Below follows a description of how those cases were selected. First, we engaged with a psychotherapy team of four, experienced, female therapists with a particular interest in management of clinical and ethical dilemmas. They also function as therapists in the cases below. We refer to them as 'the expert team'. Second, we decided what kinds of cases would work for demonstrating the applicative value of the model. Together with the expert team, we selected cases for this particular study. There were two criteria for case selection: 1) the case should involve a situation in which one of the expert team members have struggled with clinical or ethical decision-making and dilemma management, and 2) the situations had either been a) video-recorded or b) discussed with peers. In relation to the second criterion, the idea was that we would not rely on individual memory skills of what happened. This process led to a case-portfolio of challenging clinical situations. We narrowed down the case portfolio to 8 cases of non-routine decision-making processes in clinical and ethical dilemma management.

All cases have been investigated with the expert team before they were synthesised into written cases. Before the case was written down, each expert team member was interviewed about their experience of the clinical challenges they experienced during the psychotherapeutic session. Specifically, they were asked about 1) the nature of the clinical challenge during the psychotherapeutic interaction, 2) the patient's enacted psychopathology and, 3) how 
the situation was managed. During this process we relied on critical decision-making method (CDM). CDM is a semi-structured interview method that: "uses a set of cognitive probes to determine the bases for situation assessment and decision making during critical (nonroutine) incidents (for a full procedural description, see Hoffman et al., 1998). CDM is based on the concept of expert decision-making as the recognition of cue patterns in the task environment without conscious evaluation of alternatives; thus, situational awareness plays a dominant role in experts' selection of courses of action" (Clark et al., 2008:582). Finally, we conducted an extensive interview with the expert team group, to have them reflect on the task description, the pitfalls in task performances (here in terms of managing the clinical or ethical dilemma), and the possible ways for proper and dysfunctional action from an expert point of view. This group interview is used to contextualise the analytical results in a broader context of clinical decision-making in psychotherapy (see section 4).

Overall, we combine observation data (cases) with the expert team member's first-person reflections (interviews) to investigate what actually happens in naturalistic situations of clinical dilemma management. We therefore, seek to unpack important aspects in the management of clinical dilemmas (which includes decision-making), that is, what an expert within a given field does/thinks to accomplish what is needed in various organisational contexts. As Crandall et al. (2006) put it, a general goal of cognitive ethnographic research is to help "researchers understand how cognition makes it possible for humans to get things done and then turning that understanding into aids (...) for helping people get things done better" (Crandall et al., 2006:2). Finally, we use the therapists' reflections concerning the patient's psychopathology to evaluate actual performance based on observation-based case-narratives (Pedersen, 2015; Trasmundi, in press). The aim of this research is thus to shed light on a rarely investigated task in psychotherapy: clinical dilemma management, including decision-making and its relation to patient psychopathology.

The case portfolio has thus been written in collaboration with the expert team following the phase-based structure: (1) Description of the dilemma-based interaction; (2) Identification of the patient's psychopathological behaviour; and (3) Reflections on and assessments of the clinical decision-making process. Each case will be described in the Result section (section 3). Finally, the therapists discuss the psychopathology of the patients, and what kind of constraints this has for therapeutic work (section 4).

\subsection{Analytical Procedures and Steps}

The analysis consists of a systematic investigation of the three phases identified in the case description. Phase 1, Description of the dilemma-based interaction, has been analysed using procedures from multimodal interaction analysis (MMIA). A multimodal interaction analytic perspective pays attention to the complex interaction between therapist and patient that involves what is being said, but also how things are said, and what is not said (Goodwin, 2000a, 2000b; Trasmundi, 2016; Trasmundi \& Steffensen, 2016; Trasmundi \& Harvey, 2018; Trasmundi \& Linell, 2017; Steffensen, 2012). In that view, gaze, utterances, gestures and other embodied dynamics serve as cues for the therapist to sense how the patient responds, relates and engages in the interaction. The recognition of a certain embodied, behavioural pattern becomes crucial in terms of dilemma management as we demonstrate in section 3 .

In phase 2, Identification of the patient's psychopathological behaviour, we rely on the therapist's ability to link the patient's general psychopathology with the actual enacted interaction pattern (phase 1). For instance, we demonstrate that when the therapist senses the underlying emotional-cognitive dynamics that constitute the interaction, she/he is able to respond to the patient's behaviour as either psychopathological or more sensible and reflective. Phase 3, Reflections on and assessments of the clinical decision-making processs, constitutes a synthesis of the therapist's evaluation of how the actual situation was managed. This phased is represented based on interviews with the relevant expert team member (cf. section 2.1). We emphasise that in this process there might be ways in which the therapist's countertransferential reactions could play a role (Gabbard, 2005:73). As the psychopathology is rated by the therapist, we are aware that therapist perspectives could be skewed by their own relational tendencies and attachment histories. The potential role of the therapist is thus discussed in the analysis (specifically in phase 3 in the case narratives) as well as in the final discussion (section 4).

\section{Results: Eight Case-Based Narratives}

\subsection{Case 1: Reenacting the Fear of Consequences}

\subsubsection{The Dilemma-Based Interaction}

A male patient suffers from anxiety and depression and sub diagnostic narcissistic personality traits. At the very beginning of his $13^{\text {th }}$ therapy session he raises a concern that relates to his and his partner's wish for adopting a child. However, as the patient's history involves being a victim of sexual abuse, he fears that opening up about how he has been sexually assaulted as a child can become a potential liability for being approved for adoption. This 
concern is based on his doubt about whether sensitive information is shared between the therapist and social workers in cases like his. If the department of adoption can get access to his files with commentaries from the therapy sessions, he considers not saying anything about the causes of many of his anxiety problems - the sexual assaults - in therapy. If he decides to open up, the patient fears it impacts his options for adoption. On the contrary, if he decides that he should remain silent when these issues are mentioned, that decision most likely suppresses psychological progression and thus affects his well-being negatively in the long run. The patient wants the therapist to promise him that the adoption case will not be affected by what happens in therapy, but she cannot do that. The therapist believes that the patient's well-being depends on talking about and working with traumatic past events, and she needs to investigate and balance the principles of patient autonomy and non-maleficence (Beauchamp \& Childress, 1979). The therapist wants the patient to open up about sensitive topics, including sexual assaults in order to make psychological progress and get new experiences with managing difficult emotions. However, this strategy is not straightforward, as the therapist is uncertain about the procedural aspects of this dilemma (who will have access to what, and who will evaluate what and with what consequences). Further, the therapeutic interaction is characterised by scepticism on the patient's side and his psychopathological attitude emerges alongside with his omnipresent fear of consequences in general. The therapist's insecurity is manifested in her embodied behaviour: She hesitates, she uses an inconsistent argumentation style, she repeats her view on the matter, and her gestural embodiments are used to visualise how her area of competence is linked to the spatial here-and-now setting. The patient's embodied behaviour likewise reveals how his psychopathology emerges and affects the interaction, which is elaborated below.

\subsubsection{Psychopathological Behaviour}

The patient avoids engaging in dialogical interaction. For therapy to work, the therapeutic alliance between the therapist and patient must be trustful and open for exploratory behaviour. As mentioned in the introduction, The patients' previous experiences with dysfunctional relationships are easily reenacted when they find themselves in stressful situations. In this case, the therapist interprets the patient's fear of consequences as a sign of his overall psychopathology: an omnipresent fear of consequences of being open because he believes it makes him vulnerable of assaults, which inhibits him from making healthy decisions; a perspective that the patient seems unable to fully understand. The therapist observes that the patient withdraws and avoids engaging in explorative dialogue by avoiding answering questions like: "what if you..." Rather, the patient expects the therapist to solve his problem, and this psychopathological behaviour dominates the interactional dynamics. In this case, it is vital for the therapist to get the patient to acknowledge that these dynamics constrain any kind of progress. In this particular situation, the therapist eventually gets the patient to talk about his fear of consequences and they circumvent the decision-making process and emphasise a discussion about 'what is at stake' in terms of therapy.

\subsubsection{Therapist Reflections About the Clinical Management Process}

After this therapy session, the therapist described her experience of being in the dilemma-based situation as feeling powerless and constrained. Thus, she could not discuss the nuances of the dilemma with the patient due to the fact that his psychopathological behaviour constrained dialogical interaction for a long time. Even though the therapist did make progress with the patient to move forward, she felt anxious and was filled with doubt about how she managed the process. She wondered whether she pushed the patient too much, whether she did something wrong, and whether her actions could have negative consequences for his experience with being in therapy.

The therapist's self-perception indicates an expression of countertransference (cf. Gabbard, 2005:73), because her actions (as observed in the video-recordings) did in fact have a manageable function on the patient's self-perception, and he did agree that his behaviour is a manifestation of his psychopathology. It is worth mentioning, that there is a big discrepancy between the therapist's memory of the sequence and the actual management observed in the video-recordings, which can be explained by the intense emotions activated in the situated, embodied interaction. When reviewing the video, it is noticeably, that despite the patient's attempt to pressure the therapist into giving a yes or no answer, the therapist keeps underlining insecurities, doubts and nuances in the dilemma explicitly. By not subjecting to the psychopathology, the therapist attempts to enact conditions for new relational experiences for the patient that is neither submissive nor dominant but flexible, authentic and assertive.

\subsection{Case 2: Confronting the Patient With A History of Sexual Abuse}

\subsubsection{The Dilemma-Based Interaction}

A female patient diagnosed with borderline personality disorder was sexually abused by her father for 10 years during her childhood. She grew up in an environment characterised by transgressive behaviour and sexual abuse 
where her father violated her physical and psychological boundaries, and her mother ignored her suffering and did nothing to prevent or stop the abuse. Consequently, she never learned to demarcate any boundaries herself. Today, she constantly allows others to use her and treat her with disrespect and overlook her emotions, needs, desires and wishes. In therapy, the patient needs to work with those traumas in order to be capable to understand her own and other's boundaries. The clinical dilemma in this case relates to therapist's difficulty in timing when and how much she can engage the patient in trauma processing without risking transgressing the patient's boundaries in ways that would generate new traumatic experiences in the patient. It is a recurrent dilemma that emerges in the therapeutic interaction between the therapist and this patient. In this description we zoom in on the dilemma emergence during the $8^{\text {th }}$ session. As the therapist approaches the difficult emotional aspects of a trauma from the patient's childhood, the patient embodies an ambiguous interactional behaviour. That is, she oscillates between wanting to talk about her childhood traumas and resisting to do so. Specifically, the patient articulates that: "it is too much right now" and she leans her head against the wall as if just sitting in the therapeutic room is exhausting and almost impossible for her. The therapist defines the emerging dilemma in terms of being unable to interpret the patient's abilities, needs and wishes which complicates therapeutic and professional decision-making: is it too early in the therapeutic process to engage in trauma treatment? Is the therapeutic alliance not strong enough? Are they just circumventing the subject? Is the treatment confirming her psychopathology by avoiding engaging in exploration of emotions? On the other hand, the therapist fears that the patient will become suicidal, self-harming in ways that might lead to hospitalisation if the therapist confronts the patient with her avoidance strategy. In this situation the therapist decided to postpone the confrontation as she felt unable to determine the patient's emotional-cognitive state based on the ambiguous embodied actions the patient revealed in therapy.

\subsubsection{Psychopathological Behaviour}

The therapist evaluates that the patient is not in contact with her feelings and bodily reactions - other than fatigue - which inhibits her from demarcating boundaries. When she feels no boundaries, she feels no assaults. Another related primary psychopathological symptom is responsibility avoidance, that is, the therapist struggles with making the patient able to link her own emotions and actions with a responsibility for demarcating boundaries for herself and others. By avoiding responsibility, the patient is (un)consciously demanding her environment to discover her needs and protect her. When the therapist and patient enter her childhood traumas, she becomes dissociative and cannot feel her aggression and anger. In terms of embodiments, the patient's body language becomes less animated, less energetic, less dialogical and she becomes extremely tired, which is one of her primary psychopathological symptoms. In this session (as in many previous sessions), the therapist experiences that the patient immediately becomes unresponsive and emotionally absent when vulnerable topics, dissociated emotions and unpleasant memories are brought up. Her gaze, body gestures and facial expressions, as well as her general dissociative state, reinforce the vulnerability but also her tendency to avoid taking responsibility. The therapist is aware that she needs to 'do something' to enable any changes for the patient, but the patient's particular psychopathology complicates interaction. Thus, the therapist understands that all options entail immense unknown factors which can have extreme negative consequences - a risk that makes hesitation the obvious, yet not necessarily the optimal solution. In this case, the therapist choses to articulate her own insecurity in relation to this dilemma in order to cope with the situation as will be elaborated below.

\subsubsection{Therapist Reflections About the Clinical Management Process}

In this therapy session, the therapist had the feeling she embodied the role of either the assaulting father who forces the patient to do something uncomfortable against her will, or the role of the mother: a bystander, who does nothing to prevent the assault from happening. Without feeling comfortable in doing so, the therapist thus eventually utters that she has to confront the patient (but she admits she feels uncomfortable in doing so) in order to get the patient to work with her childhood traumas. She explains that this work is needed in order to understand how her traumas affect her emotions, thoughts and behaviour and the way she handles her life today. By talking openly about the dilemma, the therapist invited the patient to reflect on the dilemma in the particular situation as well as in the therapeutic process in general. The patient got an experience of being able to reflect on her own psychopathological behaviour without reducing her energy level to a point where she becomes unable to function in interaction. This strategy appeared to be a step in the direction of cooperation and building trust, and it enabled the patient to gain a new level of independence in this particular situation. This interaction might serve as a stepping stone for the patient as it becomes a new successful experience of taking responsibility of her own life.

\subsection{Case 3: Pregnancy or Abortion? Notifying the Social Services}

\subsubsection{The Dilemma-Based Interaction}

In the $25^{\text {th }}$ session, a female patient diagnosed with borderline personality disorder reveals to her therapist that she 
is pregnant. This situation becomes the subject of the next couple of therapy sessions. For nearly two years her and her husband have wished for a child, but until this point, they have been unsuccessful in achieving their dream. The patient is filled with mixed emotions in relation to the new condition of being pregnant. Even though becoming pregnant has been a goal for so long, she is not as happy as she had expected to be. She links this lack of happiness with the massive problems in her relationship and in her life in general. The patient is mentally and emotionally unstable. Her relations are unhealthy and characterised by disrespect, neglect, etc. Her husband has a massive alcohol and drug abuse. He is often aggressive, and the patient is not able to treat herself with respect in this chaotic situation. On the contrary, she conceals her husband's abuse, lies about it to her friends, family and even in therapy and she even apologises on his behalf. She tries to maintain an outward facade of idyll and perfection.

This situation raises several clinical dilemmas. The therapist understands that pregnancy is the patient's greatest wish, but she also has a great deal of concern for the unborn child. Specifically, she doubts that the patient and her husband will be able to cope with the task of parenthood. According to Danish law, the therapist is obliged to notify the social service about her concern about the patient's ability to take care of her (unborn) child. How to handle this dilemma with both empathy and severity is perceived as almost unmanageable the by therapist. If she opens up about her intention to notify the social services, if the patient completes the pregnancy, the therapist anticipates that the patient will perceive this as manipulating her to choose abortion.

\subsubsection{Psychopathological Behaviour}

The patient is unrealistic about the consequences of the decisions she makes in her life. She believes that all problems disappear as soon as she and her partner become parents. That is, she is under the illusion that her husband will no longer have a massive alcohol and drug abuse, there will be no problems in their relationships, and she will no longer have mental difficulties. Based on this logic, she does not identify any real challenges in taking care of a child, and she expresses that: "as long as I do not let the baby experience the childhood I had, everything will be just fine." The therapist uses a strategy that allows her to interact openly with the patient, as she fears she will easily judge the patient and thus prompt her to protect herself by reenacting psychopathological behaviour to an even higher degree than she is doing in the current interaction.

\subsubsection{Therapist Reflections About the Clinical Management Process}

The therapist explains how she tried to take an open stance by talking about the emergent dilemma which only increases with time. This stance-taking involves being open towards contradictory feelings within the patient's life: on the one hand realising a dream, and on the other hand not feeling as happy as expected in this situation. This perspective further initiated a reflection on how the patient's life with a child could be. However, as the therapist enacted this strategy, the patient was put in a very vulnerable situation since her mixed emotions were exposed and evaluated. Word selection, timing and empathy are therefore crucial for how the therapist handles this clinical dilemma. Also, the therapist made it clear that even though it is her personal conviction that abortion is the best solution, it is very important that the patient arrives at her own conclusion. She therefore facilitated the patient's own line of thinking, allowing the patient to articulate, reflect and evaluate her mixed emotions. Thus, "the working material" in this situation is the hint of ambiguity that the patient reveals when she feels safe and trusted. The therapist facilitated the attention towards the ambiguity in the patient's narrative. By doing so, the patient became an observer of her own narrative, and she was able to engage in dialogue with the therapist about these mixed emotions. This result is enabled by the therapist's work on the patient's psychopathological embodied behaviour in situated interaction.

A few sessions after this situation, the patient announced that she had decided to have an abortion. Again, she was filled with mixed emotions: She felt grief in letting go of her biggest dream, and she felt she lost something to hold on to in her fantasy world when life was tough. But at the same time she also felt relieved. The latter feeling was likewise experienced by the therapist.

\subsection{Case 4: Reenacting the Fear of Being Dominated}

\subsubsection{The Dilemma-Based Interaction}

A male patient diagnosed with a narcissistic personality disorder suddenly expresses anxiety symptoms in the $4^{\text {th }}$ therapy session. He fears the consequences of opening up to the therapist about the true state of his psychological well-being. He is worried that if he reveals his true feelings, the therapist will hospitalise him against his will and put him in mechanical restraint. This concern raises a dilemma related to the trust between the therapist and the patient. Meaningful therapy requires a trustworthy relationship where the patient in his own pace feels safe and protected when revealing his private thoughts, feelings and experiences (Hatcher and Barends, 2006). If handled with care, this gradual exposure of the self increases the patient's feeling of attachment and thereby enhances the 
therapeutic alliance and potentially the treatment outcome. However, the therapist has an obligation to withhold the patient if the therapist assesses a potential risk, for instance that the patient is in danger of committing suicide or is a potential threat to other people. This risk emerges in this case and the therapist fears that putting this obligation into words will increase the patient's anxiety to a level that will be difficult to manage in interaction. The therapist struggles with how she can respond to the patient in a way that calms him down but without promising something that is not possible within the Danish law of mental healthcare. She anticipates that her inability to provide the patient with the desired answer, will most likely reevoke an aggressive behaviour from the patient's side.

\subsubsection{Psychopathological Behaviour}

In this particular situation, the therapist finds herself in an interaction that is best characterised as emotionally tense and uncomfortable. The patient asks if the therapist ever could be in a situation where she needs to hospitalise and restrain him if he speaks freely in therapy. The therapist hesitates, and it prompts the patient to lean forward and stare intimidatingly at her. The silence indirectly indicates that the patient requires an answer from the therapist. Retrospectively, the therapist interprets the patient's anxiety as a reenactment of a psychopathological behaviour that relates to the patient's relationship with his older brother. The older brother used to dominate the patient as a child and one day the patient had enough and used his own growing physical dominance as an answer to the brothers torment. It is evident that the patient uses his aggression to scare people off to avoid close relationships that ultimately could destroy him. In therapy, this behaviour is understood as a need to be the dominating part in any relationship to avoid feeling inferior and vulnerable. Thus, the therapist eventually interprets the patient's aggressive embodiments as reenactments of the patient's past violent relationship with his brother. That is, the patient has made an inflexible connection between vulnerability in therapy and the idea that the therapist and the overall psychiatric system will react with dominance by the means of mechanical restraint. In that situation, the patient's negative and anxious feelings are in danger of becoming a self-fulfilling prophecy.

\subsubsection{Therapist Reflections About the Clinical Management Process}

For the therapist, the possibility of responding freely to the patient is limited by the affective state of the patient. This is evident in the aggressive and dominating interactional style in both his verbal and nonverbal behaviour. The therapist barely knows the patient and is not immediately aware of the patient's reenactments at this early stage of therapy. The therapist chooses to put the legal obligation into words and at the same time tries to make a contract with the patient. The therapist has subsequently uttered that if she had been fully aware of the dynamics related to the patient's reenactment behaviour, this dilemma could have been handled differently and in a therapeutically more convincing way. The therapist would like to have mirrored the patient's anxiety of being vulnerable and worked with his psychopathological behaviour that relates to the mindset that only the strongest survive, both physically and psychologically.

\subsection{Case 5: Reenacting the Fear of Being Responsible}

\subsubsection{The Dilemma-Based Interaction}

A male patient diagnosed with borderline personality disorder and episodically depression wants the therapist to decide for him whether or not to stop taking antidepressive medication. In cooperation with a psychiatrist he has planned to gradually phase out his medicine, but during that process the patient starts to feel worse. He easily panics and starts questioning whether the phasing out is the best solution for him. He raises this concern and requests that the therapist decides what he should do, regardless of the outcome of the decision. The therapist believes that the patient really wants to see how it is like not to be dependent on medication, but at the same time she is worried that his well-being decreases significantly if he phases out his medication. The therapist is expert in assessing the patient's health, and she is obliged to share her assessment on the matter with the patient, just as she is obliged to consult a psychiatrist. However, in this case she senses that the patient's request is a symptom of his fear of taking responsibility. If so, the this case requires that she does not express her professional opinion. The therapist therefore considers how to take the patient's psychopathology into consideration before deciding how to engage further in the interaction.

\subsubsection{Psychopathological Behaviour}

Usually the patient is perceived as unanimated: his posture is static and inactive. However, when he addresses his concern about medication, the patient becomes more vivid in his gesticulation. He leans forward, then backwards, he raises his arms over his head, crosses his fingers and lets them rest for a moment on top of his head just to let them slide across the face area. He explicitly embodies despair, impatience and aggravation. Previously, the patient has revealed a past situation to the therapist: as a child, his mother wanted him to decide whether or not she should 
leave his father. Being put in this position by his mother at such an early age filled him with anger and uneasiness, and it continues to happen when he is faced with any kinds of responsibility. This experience can be seen as a parallel to the dilemma in the therapeutic setting. However, in this case it is the therapist that feels forced into the role of the patient as a child. The patient takes the position of his mother and forces the therapist to take full responsibility for his decisions and their potential consequences, leaving her to blame if it does not work out as expected.

\subsubsection{Therapist Reflections About the Clinical Management Process}

The therapist experiences an enormous pressure to provide the patient with the reassuring answer he wants. The pressure urges her to demand the patient to make the decision himself, but in the situated interaction she did nothing, she was pacified and unable to say anything. She decided to consult her colleagues, and they discussed how the patient reenacted his past emotions when he demanded the therapist to evaluate and decide his future medication. In realising this situation, the therapist did not feel as restricted by the patient, which enabled her to embrace the complexity of the dilemma in her response to the patient. Specifically, she became able to respond to the patient's enquiry without making the decision for him. Rather, the therapist embodied the feelings the patient told he had as a teenager. While she further articulated that his mother's actions were indeed unfair, she also underlined that he as a grown man is responsible for his own decisions. She emphasised that he needs to take action, just as his mother should have done, even though taking responsibility reminds him of the old feelings and makes him feel vulnerable. This confrontation was a critical moment in the therapeutic relationship, since it became crucial for the patient's later actions. Soon after, he made an independent decision: he changed the medication plans and went back on his original doses of antidepressive medication. Likewise, the therapist got more confident in discussing the dilemmas with colleagues.

\subsection{Case 6: Dealing With Erotic Transference in the Therapeutic Room}

\subsubsection{The Dilemma-Based Interaction}

The dilemma concerns how a therapist handles an erotic transference of a male patient suffering from lifelong severe obsessive-compulsive disorder with intrusive sexual obsessive thoughts and general compulsive behaviour. At the middle of the $9^{\text {th }}$ therapy session, the patient opens up about his feelings for the therapist, which have activated increased sexual obsessive thoughts and compulsions. He has been brought up in a very religious environment, and in his youth his sexual desire had been talked about as sinful and forbidden. In therapy, he raises the concern that the therapist will evaluate him as a sinner and terminate the course of therapy when he utters his feelings. Additionally, by articulating his feelings verbally, he feels he cheats on his girlfriend. His feeling of guilt in turn increases repetitive religious compulsions of praying for forgiveness. He has never told anyone about his sexual obsessions and compulsions before. He feels ambivalent by telling the therapist about it, because he knows that suppressing his thoughts and feelings might obstruct his developmental process, but he also fears he will actually act out his impulses and hurt someone if he tells anyone. The therapist is now caught in the patient's embodied emotional ambiguity in the interaction.

\subsubsection{Psychopathological Behaviour}

Initially, the patient is ashamed when he reveals how he feels. However, when the therapist invites him to explore the topic and shows understanding, the alliance suddenly becomes dominated by an erotic transference. The patient's arousal increases, as he transgresses the norms of the therapeutic setting and process. The patient proposes the possibility of establishing a private relationship, for example by connecting through social media, or by establishing a friendship that goes beyond the therapeutic alliance. The therapeutic room is in danger of breaking down, as the inter-bodily dynamics cease to function as a condition for practicing therapy. In this state, there is little room for generating new insights into his psychopathology (Jørgensen, 2018).

\subsubsection{Therapist Reflections About the Clinical Management Process}

In the first half of the $9^{\text {th }}$ session, the therapist exhibits a curious attitude. She attempts to be professionally involved in the interaction, and she focuses her attention on her own countertransference feelings of irritation and disgust by trying to normalise and explore the patient's emotions and thoughts. When arousal increases, and the patient starts ignoring the norms and rules of the therapeutic context, the therapist feels insecure and in doubt about how to proceed. She acknowledges the importance of helping the patient to open up in order to make psychological progress and in order not to reenact the patient's experiences from his youth, while at the same time she tries to maintain a joint focus on the norms and ethical rules of the therapeutic room (Freud, 1915). Midway in the session, she chooses to outline the ethical norms and rules. Referring to these immediately activates the patient's anger, sadness and feelings of rejection. After the session the patient calls the therapist. He feels ashamed and is afraid 
that the therapist will terminate the course of therapy. He is further uncertain whether he wants to continue in therapy anyway. The therapist ensures that she will not terminate the therapy and the patient agrees to come back the following week to talk things through.

Over time, the balance between curiosity and rules appears to be helpful for the patient because he comes to understand that the romantic relationship is illusory, and at the same time, he gets a successful experience of being able to talk to someone about this sensible topic. Together they establish a setting where they can explore the patient's emotions and get a mutual understanding of how and why the patient reacts as he does without breaking down the therapeutic alliance. On the one hand, the therapeutic setting - including the asymmetric relation between the therapist and the patient - activates the patient's desire for the therapist. On the other hand, due to the interactional resources of balancing curiosity, exploration and explicit clarification of norms and rules, the patient finds himself embedded in a safe situation where he gradually starts to get curious about his own feelings. Thus, he finds out, that his erotic desires play out in many different settings where he gets positive attention (with his nurse, doctor, female students). This starts a process of corrective experiences about differentiating between feeling seen and contained and feeling in contact with his emotions. In turn, that contributes to a normalisation and understanding of his sexuality. By session 12, the patient expresses a reduction in obsessive thoughts and by session 22, the patient expresses that he is relieved, that the therapist did not act on his approximations, which would probably have made him very angry and confused. At this point in time, he has become able to regulate his emotions in accordance with social norms and rules.

\subsection{Case 7: Demands and Understanding: Writing Down Sensible Information in the Journal}

\subsubsection{The Dilemma-Based Interaction}

In the $9^{\text {th }}$ therapy session, a female patient raises fundamental doubts about her relationship with her partner. Shortly after she regrets having stated this and asks the therapist not to take any notes on this particular issue. The therapist has an official obligation to create and maintain a file on her patients based on notes from the therapy sessions. However, the specificity of these notes varies from session to session and from therapist to therapist. After each therapy session, a brief set of notes will always be drawn up. However, it is possible to omit certain details if the therapist decides to do so. In the Danish healthcare system, all patients have access to their own medical record, including all notes made by the therapist after each session. While only the patient has access to her own medical record, she lives in a relationship with a dominant partner who demands to read the notes as well. The nature of the notes has previously caused problems in their relationship, which is why the patient is alert when critical evaluations about her partner is noted by the therapist. The notes are primarily the therapist's tool, but in this situation the therapist's note-taking becomes a question of obeying the patient or going against the patient's wishes. In this case, the therapist initially avoids giving an explicit answer, but after the patient's third request, in which she directly addresses the therapist, the therapist accommodates this unusual request and succumbs to the pressure.

\subsubsection{Psychopathological Behaviour}

The patient confronts the therapist directly. She uses her first name in the end of the request and leans towards the therapist as she points at her. She demands a confirming answer immediately. The patient's threatening behaviour reinforces the impact and seriousness of the demand. Such an extraordinary action from a patient also implies a potential face threat (Goffman, 1983) for the therapist since it challenges her professional authority. Thus, the asymmetry between therapist and patient seem to be reversed for a short while: the patient demands a certain type of action or behaviour from the therapist, which is in contrast to the usual 'division of labour' in psychotherapy. Even though the therapist is unable to contain the emotional tension (she does what the patient demands), she understands what happens. The patient takes on a dominating and controlling role, similar to how her partner has a controlling behaviour over her, and similar to how her mother treated her in her childhood and adolescence. Her aggressive behaviour is thus interpreted as a reenactment of these previous relationships.

\subsubsection{Therapist Reflections About the Clinical Management Process}

The therapist describes that she immediately understands that she is caught in a dilemma, when the patient makes her request. In this dilemma she must respect the patient's autonomy in relation to her wish of having information deleted, while at the same time insisting that taking notes on central issues is a central part of her job as a therapist (Beauchamp \& Childress, 1979). In this situation, the patient's pressure made her feel uncomfortable and scared. The dilemma is further complicated by the fact that the patient's behaviour was interpreted as a reenactment of a negative interaction pattern between the patient and her partner, in which the patient is subordinate to the needs and wishes of her partner. In this respect, there is another dilemma at stake concerning the ethical principle of 
nonmaleficence (Beauchamp \& Childress, 1979). The therapist fears that giving in to the patient may in effect cause harm on the patient, as it would reproduce a destructive pattern of behaviour already present in the patient's relationship with her partner. The therapist knows that the patient has severe difficulties in demarcating boundaries in her relationship with her partner. Therefore, there is a real risk that the patient's partner reads the notes from the session. However, abiding to the wish of the patient is to reinforce a pattern of violating behaviour. The ambition of the therapist is to get the patient to see alternative ways of acting, in which it is alright to maintain her own perspective, rather than to adopt her partner's perspective. She did not succeed in this case. While on a shorter timescale the therapist may have preserved the alliance by not writing anything down, on a longer timescale, this solution is likely to create the exact opposite result.

\subsection{Case 8: The Risk of Overreaction or Non-Responding}

\subsubsection{The Dilemma-Based Interaction}

A female patient suffers from antisocial personality disorder with many reported instances of reacting violently and verbally aggressive. Throughout the course of therapy, the patient reports on violent behaviour from both sides in her current relationship. The therapist has a general ethical concern, that the patient is not motivated to work on decreasing violent episodes in her life, as she sees this behaviour as the only way to gain respect and avoid being abused by others. In one session, the patient presents a concern about her violent impulses, specifically an impulse to kill her boyfriend with a knife. In the session, the patient enacts her aggression (her primary psychopathological symptom) towards the therapist, when she is confronted with her relationship to her boyfriend. This aggression becomes the locus of interest, as the therapist needs to engage in this interaction in a way that corrects the patient's behaviour and protects herself from the patient's aggressive behaviour.

The patient has been a victim of sexual abuse from both her father and uncle. She reports that the family had an implicit acceptance of abuse, and to this day the patient remembers the abuse as a mutual consenting sexual relationship starting from birth, indicating that her father loved her unconditionally. A similar pattern developed in relation to her mother (as well as other family members), where violence was a key component in interaction. The patient does not think of these violent experiences as traumas, but as normal behaviour in close relations. The part of the patient's history that involves normalisation of antisocial behaviour, can be seen to be transferred to the therapist in this session.

In the session, the therapist finds herself in a dilemma where she is insecure about how she should manage the information given by the patient. The therapist is not confident in the patient's self-restraint both in the situated interaction but also in near future, and she fears that the patient will act out her violent impulses and harm her boyfriend. On the other hand, the therapist worries that she overreacts (for example by notifying authorities), and she thus risks damaging the patient's trust and gives the patient yet another experience of how her impulses are impossible to control and live with.

\subsubsection{Psychopathological Behaviour}

In the session, the patient leans forward, raises her voice to the level of yelling, flexes her muscles and fists, and grinds her teeth. She does not pause, when the therapist tries to stop her, and she gets very agitated when the therapist tries to intervene. However, when the therapist calls out her name in a loud, firm voice, she stops. After a short while the patient seems almost relaxed, and the therapist is able to talk to the patient about the incident with the boyfriend and the embodied reenactment of psychopathological behaviour. In this part of the session, the patient reduces the problem and expresses normalising statements such as "all of my friends hit each other" or "it is the only way you can get respect from that kind of people."

\subsubsection{Therapist Reflections About the Clinical Management Process}

The therapist experiences the patient's reenacments very strongly, and she doubts her own professional judgement in the situation: she thinks to herself, that she might be naïve, ignorant and gullible when she tries to encourage the patient to explore the consequences of violent behaviour. The therapist thus feels frightened and also angry when the patient reenacted her rage towards her boyfriend in the session. However, after her intervention, she suddenly felt completely calm, and got curious of the sudden shift from aggression to complete absence of worry. This reaction seems to represent the two modes, the patient transfers in the relation. The first mode is intense fear, anger and a sense of being violated, that might have been caused by being interrupted and intimidated by the patient's nonverbal behaviour. The subsequent feeling was a feeling of numbness and pacification, which could be understood as a countertransference, which indicates that the patient normalises psychopathological behaviour. This observation converges with the patient's childhood experiences of sexual abuse and violence that have been overlooked and normalised by her parents as well as other grown-ups in her social environment. The consequence 
of the normalisation of antisocial behaviour is a pacification of the other part, making the victim unable to change the situation.

The management of the situation thus constitutes a therapeutic change, that is, when the patient embodies this object relation, she feels powerless. The therapist felt like she was unable to stop the patient's rage in the moment, but when she called her name out loud and firmly, the patient responded and listened. The therapist then told the patient the following: "you have to stop now, because this is not a conversation when you are yelling. When you yell like that, I get scared, and then I can't think, and I need to be able to think in order to help you. So, we have to work together to make sure that we can think in here. What was it like for you when I stopped you like that?" Ideally, the patient generates new experiences in situations like this. Such experiences affect the patient's understanding of violent behaviour: it is not impossible to stop abusers (herself and others), and one can ask people to stop without violence.

\section{Discussion: Evaluation of Clinical Dilemma Management}

The eight cases demonstrate a wide range of how clinical dilemmas emerge and develop in embodied interaction and how the management is or can be related to a patient's psychopathological behaviour. The results have according to CTA procedures - been discussed and evaluated together with the therapists who all were participants in the eight cases. From that evaluation session, three overall themes came up in interview about how decision-making in clinical dilemmas is and should be managed: (1) The importance of identifying psychopathologies in clinical dilemma management, (2) What therapist can do to navigate successfully in embodied dilemma-based interaction, and (3) Pitfalls when working with psychopathologies in clinical dilemma management.

First, the importance of understanding the function of patients' embodied behaviour when dilemmas emerge in interaction was emphasised by the therapists and it became evident from the analysis of the eight cases. One of the therapists' uttered:

It becomes further complicated to discuss real clinical challenges with the patient when it is the psychopathology that talks. You can feel the psychopathology talking when the degree of interactional freedom decreases. That is, when the patient starts demanding, becomes threatening or leaves everything up to you to decide. Having a real discussion, by going through various scenarios, is not an option in such cases. There is only one fixed perspective on the matter.

The identification of the patient's behaviour, either as a pattern of flexible behaviour (the ability to listen and engage in exploratory dialogue) or as a psychopathological behaviour (the fixated and reenacted behaviour that inhibits situated sensitivity), is crucial in order to manage the decision-making involved in an clinical dilemma, as we observed in the eight cases.

Second, when discussing what therapists can do to navigate successfully in embodied dilemma-based interaction, emphasis was on picking up those cues in embodied behaviour that reveal the patient's psychopathological behaviour. Further, the therapists also addressed how explicating the dilemma was a strategy that allows for shared vulnerability and trust to emerge from authentic engagement. A therapist formulated it like this:

Within that little interactional space, we have two possible paths to follow as therapists: Either we mess up and strengthen the patient's psychopathological behaviour - for instance by giving in and do what the patient demands - or we can use the situation as an opportunity to work with their psychopathological behaviour in situ. That is, we can make it clear to them, that at this moment, we have a unique situation for dealing with their challenges, by making them aware what they do, how they feel and how they can move on from that point.

When the therapist senses the underlying emotional-cognitive dynamics that constitute the interaction, she/he is able to respond to the patient's behaviour as either psychopathological or more sensible and reflective. Given this state of embodied sensitivity and inter-bodily understanding, the therapist is enabled to share her responsibility for the decision-making process with the patient.

Based on the analysis of the case narratives, the therapists became aware of the fact that clinical dilemmas emerge again and again in psychotherapy, both as small-scale constraints and as crucial questions about life and death. They felt a strong connection as their experiences and feelings related to powerlessness and anxiety were now shared and publicly discussed with colleagues. The analysis illustrates actual dilemma management, and this illustration might impact on how we address, evaluate and understand clinical dilemma management, which again can contribute to the reduction of moral distress amongst healthcare practitioners, as well as amongst patients.

Finally, the critical aspects of understanding clinical dilemma emergence in relation to psychopathology was 
addressed amongst the expert team. One expert therapist utters:

The real challenge is that our knowledge of the patient's psychopathology becomes a bias in perceiving the patient's actions as meaningful. For instance, when you fear the consequence in a situation where all people would fear the consequences, it becomes difficult to decide whether it is the psychopathology that talks or whether it is a more natural reaction.

This third theme raises multiple important aspects in relation to clinical dilemma management. First, it was discussed what successful management is? In the cases above, some of the situations are managed with more difficulty than others. Some experts concluded that they failed, others that they felt incompetent etc. However, a therapist addresses that:

Sometimes we must 'fail' to know what is at stake and to be able to articulate what is at stake for the patient. In therapy, one gets unlimited chances, which means that it is never too late to address the dynamics in the therapeutic room.

Therapeutic interaction develops on a long timescale, which gives the therapist the opportunity to go back and forth in the interactional trajectory and talk about previous reactions and to experiment with enaction of different embodied strategies. In that sense, 'failing' is important as it prompts changes that can be investigated in relation to the patient's psychopathology when managed carefully.

Finally, while it is the therapists themselves that rate the psychopathology of the patients, the therapists' own countertransferential reactions might have played a crucial role given the fact that the therapists' perspectives could be skewed by their own relational tendencies and attachment histories.

\section{Conclusion: Limitations and Future Research}

This paper investigated a wide range of how clinical dilemmas emerge and develop in embodied interaction in psychotherapy and how the management is or can be related to a patient's psychopathological behaviour. We suggested approaching clinical dilemma emergence as a therapeutic-relevant possibility for managing patient behaviour due to the fact that dilemma-based interactions most often involve reenactments of psychopathological behaviour grounded in the present embodied interaction. The paper mapped out particular embodied dynamics in interaction that appear to be bound up with patient psychopathologies, such as fixated behaviour that inhibit dialogue, and it demonstrated the value of treating a patient's psychopathology - when manifest in the clinical dilemma - as an opportunity for the therapist to facilitate a benign therapeutic process. Given this state of embodied sensitivity and inter-bodily understanding, the therapist becomes able to share the responsibility in the decision-making process. Within the analytical section, we have given examples of how clinical dilemmas in psychotherapy have been managed. We further elaborated on how the therapists involved in those decision-making processes felt powerless and momentarily defenceless due to the fact that patients' psychopathologies are decisive for the interaction trajectory leaving the therapist with suboptimal conditions for enacting her expertise.

Specifically, to be successful in clinical dilemma management, requires that the therapist is able to manage the interaction, that is, $\mathrm{s} / \mathrm{he}$ can navigate in a supportive way that enables the emergence of rapport and trust. Fonagy and Allison (2014) and Bateman and Fonagy (2012) invite therapists to take one's own as well as the other's perspective into account in the attempt to establish epistemic trust through embodied interaction. By doing so, the interaction functions as an emergent positive attachment experience for the patient rather than a relived traumatic relationship, which we further demonstrated in the more successful cases above.

The limitations of the study are related to the qualitative nature of the data. The sample size is small ( 8 cases). Further, and, as we mentioned above, it is the therapists themselves that rate the psychopathology of the patients, and such self-reported data are taken at face value. However, the approach has enabled a detailed understanding of the micro-interactive dynamics that are at stake in clinical dilemma management. Specifically, this research has established a window into how psychotherapists manage clinical dilemmas (successfully or not) through embodied interaction, which involves an interpretation of enacted inter-bodily dynamics (verbal and non-verbal). This illustration might impact on how we address, evaluate and understand clinical dilemma management, which again can contribute to the reduction of moral distress amongst healthcare practitioners as well as amongst patients (cf. section 4). Future research can build on such results which pave the way for a more embodied code of ethics, and which, in turn, has consequences for the theoretical assumptions that inform the models and guidelines for action in practice. Eventually, these results might impact on how we address, evaluate and understand clinical and ethical dilemma management, which again can contribute to the reduction of moral distress amongst healthcare practitioners as well as amongst patients. 


\section{Acknowledgements}

This work was supported by the Velux Foundation (Grant no. 10384). Further, we thank all employees, patients, and psychotherapists at the outpatient clinic for anxiety and personality disorders at Brønderslev Psychiatric Hospital, Denmark. Without their time and expertise, this research would not have been possible.

\section{References}

Bateman, W., \& Fonagy, P. (2012). Handbook of Mentalizing in Mental Health Practice. American Psychiatric Association Publishing.

Beauchamp, T. L., \& Childress, J. F. (1979). Principles of biomedical ethics. Oxford: Oxford University Press.

Bowlby, J. (1969). Attachment and Loss (Vol 1: Attachment). London, Hogarth Press/Institute of Psycho-Analysis.

Brenner, C. (1982). The mind in Conflict. New York, International Universities Press.

Bruun, H., Lystbaek, S. G., Stenager, E., Huniche, L., and Pedersen, R. (2018). Ethical challenges assessed in the clinical ethics Committee of Psychiatry in the region of Southern Denmark in 2010-2015: a qualitative content analysis. BMC Medical Ethics, 19, 62. https://doi.org/10.1186/s12910-018-0308-z

Chipman, S. F., Schraagen, J. M., \& Shalin, V. L. (2000). Introduction to cognitive task analysis. In J. M Schraagen, S. F. Chipman \& V. J. Shute (Eds.), Cognitive Task Analysis (pp. 3-23). Mahwah, NJ: Lawrence Erlbaum Associates.

Clark, R. E., Feldon, D., van Merriënboer, J., Yates, K., \& Early, S. (2008). Cognitive task analysis. In J. M. Spector, M. D. Merrill, J. J. G. van Merriënboer, \& M. P. Driscoll (Eds.), Handbook of research on educational communications and technology (3rd ed., pp. 577- 593). Mahwah, NJ: Lawrence Erlbaum Associates.

Crandall, B., Klein, G., \& Hoffman, R. R. (2006). Working Minds: A practitioner's guide to cognitive task analysis. Cambridge: MIT Press. https://doi.org/10.7551/mitpress/7304.001.0001

Coffey, J. W., \& Hoffman, R. R. (2003). Knowledge modeling for the preservation of institutional memory. Journal of Knowledge Management, 7(3), 38-52. https://doi.org/10.1108/13673270310485613

Cooke, N. J. (1994). Varieties of knowledge elicitation techniques. International Journal of Human-Computer Studies, 41, 801-849. https://doi.org/10.1006/ijhc.1994.1083

Cowley, S. J. (2014). Human Language and Sensorimotor Contingency. In J. M. Bishop \& A. O. Martin (eds.), Contemporary Sensorimotor Theory (pp. 235-255). Dordrecht: Springer. https://doi.org/10.1007/978-3-319-05107-9_16

Fairbairn, W. R. D. (1940). Schizoid factors in the personality. In: Psychoanalytic Studies of the Personality (pp. 3-27). London: Routledge \& Kegan Paul, (1952).

Fonagy, P., \& Allison, E. (2014). The role of mentalizing and epistemic trust in the therapeutic relationship. Psychotherapy, 51(3), 372-380. https://doi.org/10.1037/a0036505

Fonagy, P. (2001). Attachment Theory and Psychoanalysis. New York, Other Press.

Freud, S. (1915). Observations on Transference-Love (Further Recommendations on the Technique of Psycho-Analysis III). The Standard Edition of the Complete Psychological Works of Sigmund Freud (Volume XII) (1911-1913): The Case of Schreber. Papers on Technique and Other Works, 157-171.

Gabbard, G. O. (2005). Psychodynamic Psychiatry in Clinical Practice (4th ed.). American Psychiatric Publishing, Inc.

Goffman, E. (1983). The interaction order. American Sociological Review, 48(1), 1-17. https://doi.org/10.2307/2095141

Goodwin, C. (2000a). Action and embodiment within situated human interaction. Journal of Pragmatics, 32, 1489-1522. https://doi.org/10.1016/S0378-2166(99)00096-X

Goodwin, C. (2000b). Practices of color classification. Mind, Culture and Activity, 7(1-2), 19-36. https://doi.org/10.1080/10749039.2000.9677646

Hatcher, R. L., \& Barends, A. W. (2006). How a return to theory could help alliance research. Psychotherapy: Theory, Research, Practice, Training, 43(3), 292-299. https://doi.org/10.1037/0033-3204.43.3.292

Hoffman, R. R., Shadbolt, N. R., Burton, A. M., \& Klein, G. (1995). Eliciting knowledge from experts: A 
methodological analysis. Organizational Behavior and Human Decision Processes, 62(2), 129-158. https://doi.org/10.1006/obhd.1995.1039

Hoffman, R. R., Crandall, B., \& Shadbolt, N. (1998). Use of the critical decision method to elicit expert knowledge: A case study in the methodology of cognitive task analysis. Human Factors, 40, 254-277. https://doi.org/10.1518/001872098779480442

Jonassen, D. H., Tessmer, M., \& Hannum, W. H. (1999). Task analysis methods for instructional design. Mahwah, NJ: Lawrence Erlbaum Associates. https://doi.org/10.4324/9781410602657

Jørgensen, C. R. (2018). Den psykoterapeutiske holdning. Hans Reitzels Forlag.

McWilliams, N. (2004). Psychoanalytic psychotherapy: A practitioner's guide. New York, NY, US: Guilford Press.

Meichenbaum, D. (2008). Core tasks of psychotherapy/counseling: What expert therapists do. www.melissainstitute.org (page consulted April 29, 2019). 76-89.

Molewijk, B., \& Reiter-Theil, S. (2016). The particular relevance of clinical ethics support in psychiatry: concepts, research, and experiences. Clinical Ethics, 11(2-3), 43-4. https://doi.org/10.1177/1477750916660854

Ong W.Y., Yee C.M., \& Lee A. (2012). Ethical dilemmas in the care of cancer patients near the end of life. Singapore Med J., 53(1), 11-6.

Pedersen, S. B. (2015). The cognitive ecology of human errors in emergency medicine: an interactivity-based approach (Ph.d. thesis). Odense: University of Southern Denmark.

Steffensen, S. V. (2012). Care and conversing in dialogical systems. Language Sciences, 34, 513-531. https://doi.org/10.1016/j.langsci.2012.03.008

Trasmundi, S. B. (in press). Errors and Interaction in Emergency Medicine: A Cognitive Ethnography. Amsterdam: John Benjamins.

Trasmundi, S. B., Steffensen, S. V., Wrist, K. K., Bruun, H., \& Jensen, T.W. (forthc). The Emergence and Management of Embodied, Ethical Dilemmas in Psychotherapy: A Qualitative Study. BMC Medical Ethics.

Trasmundi, S. B. (2016) Distribueret kognition og distribueret sprog: analyse af kognitive events $\mathrm{i}$ en akutmedicinsk social praksis. NyS, 50, 55-85 speciel issue - Ny kognitiv sprogforskning. https://doi.org/10.7146/nys.v1i50.23798

Trasmundi, S. B., \& Steffensen, S. V. (2016). Meaning emergence in the ecology of dialogical systems. Psychology of Language and Communication, 20(2). https://doi.org/10.1515/plc-2016-0009

Trasmundi, S. B., \& Linell, P. (2017). Insights and their Emergence in Everyday Practices: The Interplay between Problems and Solutions in emergency medicine. Pragmatics \& Cognition; 24(1), 64-92. https://doi.org/10.1075/pc.17002.tra

Trasmundi, S. B., \& Harvey, M. (2018). A Blended Quantitative-Ethnographic Method for Describing Vocal Sonofication in Dance Coaching. A special issue of the Psychology of Language and Communication, 22(1). 198-229. https://doi.org/10.2478/plc-2018-0009

\section{Copyrights}

Copyright for this article is retained by the author(s), with first publication rights granted to the journal.

This is an open-access article distributed under the terms and conditions of the Creative Commons Attribution license (http://creativecommons.org/licenses/by/4.0/). 